Check for updates

The BMJ

Cite this as: $B M J 2021 ; 375: \mathrm{n} 2557$ http://dx.doi.org/10.1136/bmj.n2557 Published: 20 October 2021

\title{
Covid-19: Prioritise vulnerable patients to prevent further deterioration, says charity
}

\section{Elisabeth Mahase}

Clinically extremely vulnerable people, who have been asked to shield during the covid pandemic, have been left with "significant unmet health needs and worsening mental health" and should be prioritised by the NHS to ensure their conditions do not deteriorate further, the Health Foundation has said.

Research by the charity has found that, at the peak of the first wave of covid-19 in April 2020, mortality in this clinically vulnerable population was more than 2.5 times that in England's general population (one in 2500, or $0.039 \%$, compared with one in 7000 , or $0.014 \%) .{ }^{1}$ By the end of August 2020 this group accounted for $19 \%$ of all deaths, despite making up only $4 \%$ of the total population.

This group of patients was also deeply affected by reorganisation of NHS services during the pandemic, with planned admissions in this population

decreasing by $51 \%$, outpatient appointments by $48 \%$, emergency admissions by 32\% (April 2019 to April 2020), and $A \& E$ attendances by $42 \%$.

Kathryn Marszalek, senior analytical manager at the foundation, said, "Action is now needed by those planning the recovery at local and national levels to address the unmet need for NHS care and worsening mental health. Failure to prioritise the needs of the clinically extremely vulnerable population will inevitably result in further deterioration in their health, putting additional pressure on the NHS, which is already struggling to deal with a massive backlog of care."

More than four million people were identified as clinically extremely vulnerable and advised to shield. However, there were problems in the way the shielding list was compiled and in the support given to those identified, mainly because of gaps in data and issues with data sharing. ${ }^{2}$ A report by the House of Commons Public Accounts Committee found that at the start of the pandemic the UK government failed to reach up to 800 ooo clinically extremely vulnerable people who had been added to the shielding list, largely because of missing or incorrect telephone numbers, meaning they could not get support such as food parcels. ${ }^{3}$

Poor communication with clinically vulnerable people is still an issue. After the government announced that immunosuppressed patients aged over 12 should be offered a third primary dose, while vaccine boosters would also be given to groups considered at risk, many patients have been left confused as to who should be recalling them for a third primary dose, whether they will also be given a booster (a fourth dose), and where to get their vaccines. ${ }^{4}$
The Health Foundation researchers said that in the future further investment in data sharing and data quality will be essential to ensure that the NHS has a complete picture of the needs of clinically extremely vulnerable people. This will enable services to be designed and delivered to meet these needs and will mean that in the event of future pandemics people at the highest risk of poor outcomes can be more easily identified and supported.

1 Hodgson K, Butler JE, Davies A, et al. Assessing the impact of covid-19 on the clinically extremely vulnerable population. Health Foundation. Oct 2021 https:/www.health.org.uk/publications/reports/assessing-the-impact-ofcovid-19-on-the-clinically-extremely-vulnerable-population.

2 Wise J. Covid-19: Extra 1.7 million people in England are asked to shield. BMJ 2021;372:n467. doi: 10.1136/bmi.n467 pmid: 33597119

3 Mahase E. Covid-19: Government's shielding scheme failed thousands of clinically extremely vulnerable people, say MPs. BMJ2021;373:n1033. doi: 10.1136/bmj.n1033 pmid: 33879475

4 Hodes S, Majeed A. Covid-19 vaccines: patients left confused over rollout of third primary doses. BMJ Opinion. Oct 2021. https://blogs.bmj.com/bmj/2021/10/15/covid-19-vaccines-patients-leftconfused-over-rollout-of-third-primary-doses.

This article is made freely available for use in accordance with BMJ's website terms and conditions for the duration of the covid-19 pandemic or until otherwise determined by BMJ. You may use, download and print the article for any lawful, non-commercial purpose (including text and data mining) provided that all copyright notices and trade marks are retained. 